\title{
Study of the Film in the Visual Cultural Context
}

\author{
Jinliang Cao
}

Zhijiang College of Zhejiang University of Technology, Shaoxing, Zhejiang, 312000

\author{
Keywords: Film, Visual Cultural Context, Society Phenomenon
}

\begin{abstract}
Today, we are in a time with rapid development of science and technology, the media constantly updated and the information extremely explosive. The development of modern technology, especially information technology, communication technology, automation technology and laser technology and other high-tech are widely used in various arts and culture activities, it has brought a revolutionary impact on the existence of contemporary culture and art, leading to the rise of emerging leading cultural form and the update of the traditional cultural form. And the most impressive cultural form is the visual culture. The film has become the mainstream form of today's film art, occupying an important position in the film market. For the film creator, the film is the object of reference and imitation; for the film viewers, the film has brought an unprecedented visual feast; and in the field of film researchers, the film should appear deeper social and cultural reasons. The emergence of the film depends mainly on the support of technological progress on the surface, but the underlying reason is the visual culture of the visual elements.
\end{abstract}

\section{Introduction}

When the traditional art point of view emphasizes that the real works of art should make the soul of the sublimation, purification and promotion, in short, emphasizes a recipe that can both get aesthetic pleasure and good for physical and mental health, the film must always less than literature. As a seventh art developed by the craft, it is clear that its appearance is closely related to industrial production and commercial interests, and its acceptance is targeted to the public, and the effect of the purpose is the entertainment of the public. Thus the film from the beginning is the most popular mass art, is a mass culture of the media. It is with the daily life is inextricably linked. Its civilians, its visual intuition, and even its instantaneous perishable features, both show it as the art of mass art. In many cases, social and cultural elites always think that the public is easy to mislead the crowd. So, when the film is a visual culture in a real life set off wave, it had to worry about its role in modern social culture. Especially an art is also a commodity and will be subject to an invisible but very powerful force of the traction, which is consumption. The reality of the development of visual culture has proved that the film as a medium, as a way of life, it affects, changes, shape our daily work, communication, entertainment and even the inner world of the activities of the way.

\section{The Characteristics of Movies in Visual Cultural Context}

One of the most important features of the film is to weaken the narrative features, the pursuit of audio-visual pleasure. So that people do not need to think deeply about the film contains the suspense and expression of meaning, turn immersed in the film show the magnificent, strange, strange, thrilling and other landscape impact. Its type is generally classified as science fiction film, suspense films, martial arts films, horror films, art films and so on. However, from the analysis of film elements, the film for the pursuit of audio-visual pleasure, usually stressed the following aspects: the film as an artistic expression, whether it is stressed the narrative or the pursuit of landscape, the story of the film background settings are the basis of film expression. Traditional narrative film focuses on the documentary function of the film, in the background set will not be too far away from the real life, the purpose is to lead the audience into another relatively real world, access to the film with the narrative experience or emotional experience. Such as Jia Zhang Ke's "Hoh Xil", the lens at the perennial in the Tibetan Plateau to protect the Tibetan antelope and even the expense of the workers. The background of the film is based on the urgency of protecting the 
Tibetan antelope and the hardships of the work, with the approximate record of the presentation, the people into the desolate but hidden crisis. In the Tibetan antelope clear eyes and shocking hunting comparison, the audience as their own into the film world, causing people to protect the Tibetan antelope's enthusiastic attention and long thinking. "Three Gorges good" to the Three Gorges Project as a film background, with simple and simple way, the narrative focus on every detail of the story, with the film main line - tracing the start, the film is divided into smoke, wine, tea, sugar four parts, which represents the Chinese people's ordinary life, but also have their own meaning. The film focuses on the narrative shows the underlying social landscape and real contradictions.

In the movie world, beyond the speed of light running, flat to the air, twist to escape the bullet, thrilling chase and so on the lens everywhere. These exaggerated movements, made up of short lenses, give people an immersive and spirited psychological stimulus. People have no intention to pay attention to the false degree of these action design and dazzling action together with exciting voice, let people drunk again and again in a very similar but never tired of the visual enjoyment. To martial arts films, for example, the traditional martial arts film is a real trick, the actors themselves need to have a certain martial arts skills. To create a pioneer of China's martial arts film star Bruce Lee and itself is the founder of Jeet Kune Do, the real effort to make many of the Chinese and foreign combat master whom admiration. Li Xiaolong on the screen shows the reality can do the same kung fu action, to bring people is the real beauty of the work. Later martial arts star Jet Li, born Shaolin Temple, won the fifth national martial arts champion. Its premiere of the early films such as "Shaolin Temple" shows the charm of traditional Chinese martial arts, the film to bring people not only a temporary visual enjoyment, but also led to the enduring Shaolin Temple martial arts boom. Jackie Chan is also born martial arts class, since the small martial arts, the performance of the film is to rely on their own martial arts training and film martial arts guidance level. Jackie Chan said in an interview: my film has not used a substitute, action design is the reality of ordinary people and this is the traditional martial arts film is different from the charm of contemporary martial arts film.

\section{The Visual Analysis of the Film}

We can see that the invention of photography as the first wave of visual culture is also the basis and direct cause of film production. It is regarded as the second wave of modern visual culture. The tide logo is directly the film itself; the real sense of the rise of the visual culture era and the film is also based on the emergence of high-tech computer digital technology. Therefore, the two are generated in the time dimension is basically the same, there is a development in the development of the relationship between each other. The development of the film enriched the visual culture research, and the rise of the visual culture also had a profound impact on the film. On the other hand, the visualization of contemporary society has shown a trend of intensification. The advent of the "reading time", the culture all-pervasive, the super-scale development of the network culture, and even the aesthetic enjoyment of the daily life this era is already a real visual society. Among them, the "image" as the core of the film and television art has replaced the novel and other literary form of art as the current visual culture era of decent art, its appeal to the public more than any 'language' as the center of the art. Become the representative of the center of the visual culture of the center of the art, the reason is that "the film with other forms of art, both the performance of people's emotions, but also the performance of people's thinking, and is with the reality of people, king, light, color quality of the vivid image of the screen to show, whether it is silent film, or a sound film, and whether it is documentary, expressionism, or traditionalism, modernism and even the overall integrated film, all the screen as the basic elements of thinking and the main The film is the use of the activities of the screen and sound thinking of the combination of thinking, time and space in line with the plastic arts.

\section{Film Creation based on the Visual Concept}

The development of visual culture makes visual and visual understanding an important dimension 
of contemporary cultural production, dissemination and acceptance of activities, facilitating the replacement of stories or reading books by the film, thereby pushing the image to the dominant position. With the rapid development of visual culture, people's attention to the real world is increasingly controlled by the way of representation. The whole real world characterization is more likely to lead to the separation between realistic records and characterization. Today, we are in an image production, circulation and consumption of the period of rapid expansion, living in which people on the one hand, visual demand and visual desire rising; the other hand, the culture of a high degree of visualization and media for people to watch more likely and optional. With the development of visual culture is closely related to the creation of the film is inevitably seriously affected. The film is also a representation of the reality of the situation, but the development of visual culture makes the world be grasped as an image, the real symbol instead of the real itself, and as a reality of the situation of the film is further demonstrated the screen world and the real world between the separations. Specific performance in the film creation is to "unfamiliar" image to attract the audience.

The film also by means of clothing props, lighting, color combinations and other elements constitute a common visual image. These visual images are becoming more and more realistic in external form, but in essence they are far from reality. The film through the high-tech digital technology to create real life completely does not exist in the realistic scene, completely digest the film's innate "record" nature, brought endless visual wonders at the same time, but also fundamentally changed the traditional The film "to reflect the reality of reality," the language attributes, replaced by "false imitation of reality," the screen space, so that the original film and the reality of the close relationship between the completely shattered. "The authenticity of the film is essentially a fantastic reality, if the traditional film in this fantastic truth also retains the authenticity of the artistic performance and the reality of the real environment is relatively true, then the computer digital technology into the film After the "real" is also in the East. "Film creation" unfamiliar ", its essence is to digest the traditional film by virtue of the real elements. "The art of cinema has never been the same as the reality itself, but the record nature of the camera will be a vivid face presented to the audience, one by one in front of the camera in the real story of the film art of this' second true 'It is an important reason why many movie viewers are putting in the truth of the film. "The traditional charm of this tradition is replaced by the virtual scene of the film, the film from the surface to create a delicate and real strange world, in fact, more obscure" ", In the film and the reality between the farther and farther.

\section{Conclusion}

The birth and development of the film has brought new vitality to the art of cinema. The progress of technology has supported the glamorous publicity of the expressive performance of the landscape film, and the combination of the visual culture shows the sustainable development of the follow-up force. But the film is the new type of film, its development is not yet mature, on the one hand the traditional film's spiritual core is digested, on the other hand the film's own unique character is still at the running and adjusting stage. At present, there is a clear artistic abundance weakened the status quo in the domestic film.

\section{References}

[1] Yan Chunjun. Film - the history of the film and a naive period [J]. Film Art, 2006 (05)

[2] Bao Pengcheng. Visual Desire and Film [J]. Film Art, 2006 (04)

[3] Liu Yan. Baudrillard's postmodern media theory and the construction of media reality [J] .International News, 2005 (03)

[4] Zhou Xian. Three problems of visual culture[J]. Seeking Journal, 2005 (03)

[5] Qilin. Film charm of the source[J]. Film Art, 2005 (03) 
[6] Zhang Rongyi, Peng Yongzhen. From the perspective of visual culture on the interpretation of the film[J]. Journal of Xiangfan University, 2005 (01) 